\title{
Prevalence estimates for hypertension in Latin America and the Caribbean: are they useful for surveillance?
}

\author{
Pedro Ordúñez, ${ }^{1}$ Luis Carlos Silva, ${ }^{2}$ María Paz Rodríguez, ${ }^{1}$ \\ and Sylvia Robles ${ }^{1}$
}

ABSTRACT Objective. To apply a recently proposed model and assessment tool created by the authors for critically evaluating the data available on the prevalence of hypertension in LAC and assessing their usefulness for surveillance.

Methods. A bibliographic search to identify all publications that estimated the prevalence of hypertension was performed. Each of the papers located was assessed using a critical appraisal tool.

Results. Of the 58 studies published between 1966 and 2000, only 28 of them (48\%) met the critical threshold to be considered useful for surveillance purposes. The distribution of the 28 studies in terms of their usefulness for surveillance was as follows: minimally useful, 16 studies; useful, 8 studies; and very useful, 4 studies. Several methodological shortcomings were identified, from inadequate sampling procedures and sample size to the poor quality of the primary data for planning purposes.

Discussion. Published studies on the prevalence of hypertension in Latin America and the Caribbean have, as a whole, limited usefulness for surveillance activities.

Key words Surveillance, prevalence, hypertension, risk factors, research methodology.

It is estimated that over the next 10 years, some 11 million people in Latin America and the Caribbean (LAC) will die from cardiovascular diseases (1). Nearly $23 \%$ of these deaths will occur among people under the age of 60 , which clearly represents premature mortality that can be prevented or delayed. Research has demonstrated that

\footnotetext{
1 Pan American Health Organization, Division of Disease Prevention and Control, Program on NonCommunicable Diseases, Washington, D.C., United States of America.

2 Instituto Superior de Ciencias Médicas de La Habana, Vicerrectoría de Investigaciones, La Habana, Cuba. Send correspondence to: Luis Carlos Silva, Instituto Superior de Ciencias Médicas de La Habana, Vicerrectoría de Investigaciones, Calle G y $25,6^{\circ}$ piso, Plaza, La Habana, Cuba; e-mail: 1csilva@ infomed.sld.cu
}

much of this disease can be prevented if known risk factors are reduced (2). Therefore, in order to develop public health policies and programs it is necessary to know the prevalence and distribution of risk factors in the population, as well as trends in different population groups. Risk factor surveillance is thus clearly an important tool for the prevention of noncommunicable diseases.

Hypertension is one of the most important risk factors for major cardiovascular diseases, such as cerebrovascular disease and ischemic heart disease, which are the leading causes of premature death among adults in most countries. Maintaining normal blood pressure can significantly re- duce mortality from cardiovascular disease, so hypertension clearly poses a real challenge to public health $(3,4)$.

Based on survey data, it has been estimated that the prevalence of hypertension in LAC ranges from $8 \%$ to $30 \%$ (5). While several risk factor surveys looking at one point in time have been conducted in LAC, their results are not comparable across countries and over time. In addition, there is a broad variability in a number of those surveys' characteristics, including their geographical scope (national, regional, chosen sites, etc.), diagnostic criteria used for classifying individuals, age groups considered, and procedures for data collection and sampling (6). 
Furthermore, concerted sustainable action is currently lacking that would enable health systems and services, especially in LAC, to develop strategies and programs that are both efficacious and efficient. One of the barriers to the development of efficient programs is that LAC countries have incomplete information on the magnitude of the problem.

Taking into account this situation, the objective of this paper is to apply a recently proposed model and assessment tool (6) in critically evaluating the available studies on the prevalence of hypertension in LAC and assessing the usefulness of their information for surveillance.

\section{METHODS}

In the first phase of our study, we carried out a bibliographic search to locate all the publications that estimated the prevalence of hypertension in LAC, without a timeframe restriction. In our second phase, we assessed each of the papers that we had located, using a critical appraisal tool created to evaluate the usefulness that riskfactor prevalence studies have for surveillance (6).

\section{Bibliographical search}

Published original articles can be found through a straightforward literature search, but the process becomes increasingly difficult as one tries to identify additional, unpublished materials. One approach is to break down the study question into components and then use appropriate methodological filters (study design) to help find the bulk of the literature. Using search-term synonyms and readjusting search components may expand the search findings.

To protect against publication bias and to ensure that as much as possible of the relevant data were included in the appraisal, we used a variety of sources to identify studies, in a process that may prove useful for other, similar investigations. First, we checked on whether appropriate systematic re- views already existed. Such studies may provide specific answers, or they may offer a starting point for identifying the studies themselves. Second, to identify articles that reported findings for prevalence studies and surveillance for hypertension, we conducted title searches in several medical literature databases, including the PubMed one operated by the National Library of Medicine of the United States of America, and other databases operated by the Latin American and Caribbean Center on Health Sciences Information unit of the Pan American Health Organization (BIREME). To narrow the search results as much as possible to the studies of interest, we used methodological filters to restrict the search criteria, e.g. (prevalence study AND hypertension AND [name of country]). Third, we included gray literature such as unpublished studies, reports, and conference presentations. This can be accomplished through hand-searching the bibliographies of identified journals and of books related to the topic. Ministries of health and other, similar focal points may also provide additional gray literature.

\section{Evaluation of the documents found}

In the second phase, we read and assessed the studies we had located. These were evaluated by at least two revisers, using the assessment tool mentioned earlier (6). All the disagreements that came up in this evaluation process were resolved by consensus.

Our tool for assessing a scientific report or article consists of 19 questions, which are answered based on what is explicitly communicated in the study report. The evaluation tool requires that a paper meet a certain minimum threshold in order to be considered useful for surveillance purposes. Four basic conditions must be satisfied for a paper to meet this threshold: 1) the study must be a population-based one, 2) the sampling design must be described, 3) the sampling design must be probabilistic, and 4) estimates must be broken down by sex and welldefined age groups. Papers that first meet these four conditions are then assessed using the instrument's remaining, complementary 15 questions and assigned a point score in order to evaluate how useful they are for surveillance. The total score for those 15 questions will be between 0 and 100 .

Each paper is classified as follows:

- not useful: it does not meet the minimum threshold of satisfying the 4 basic questions

- minimally useful: it reaches the threshold but receives a score of less than 35 points on the 15 scored questions

- useful: it receives 35-69 points

- very useful: it gets 70 points or more

With the studies that we found to meet the minimum threshold (the four basic questions) and were thus considered useful for surveillance, we extracted, summarized, and analyzed the relevant information related to hypertension.

\section{RESULTS}

Our bibliographic search found 69 studies published between 1962 and 2000. Of the 69 reports, 54 of them were published after 1990. We excluded 11 of the 69 papers because they only tangentially touched on the subject of hypertension, or they were literature reviews. We evaluated the 58 remaining documents using our assessment instrument whether or not they had first satisfied the four basic criteria, because it was crucial to identify and describe the methodological shortcomings under each complementary aspect and for the hypertensionspecific questions under consideration. Our findings for the 58 papers are summarized in Table 1, which reports on the 19 aspects that we considered and the percentage of the papers that met each of the assessed conditions.

As can be seen in Table 1, various shortcomings were found with the studies that we assessed. Key among them were two relating to handling the sample: 1) calculating estimates according to the sampling design (question 
number 7) and 2) reporting the errors of the estimates according to the sampling design (question number 9). It is certainly alarming that only $10 \%$ of the studies assessed reported the errors of the estimates according to the sampling design. In addition, in spite of the fact that $69 \%$ of the studies indicated that they had used probabilistic sampling procedures, only $26 \%$ of them calculated estimates according to the sampling design.

Another inadequacy related to the quality of the primary data. The percentage of the studies in which the personnel received training on data collection was unfortunately very low, as was also the percentage of studies that used certified instruments and observers. Only slightly over $40 \%$ of the studies indicated they had used some quality control procedure.

Also lacking was reporting on crucial aspects of surveillance, such as the extent to which the persons in need of care were aware of their condition. Similarly, few of the papers indicated how many of those persons were under treatment and how many of them had their blood pressure under control. In addition, only $55 \%$ of the 58 studies reported the mean blood pressure.

Of the 58 papers that we assessed, only 28 of them $(48 \%)$ met the critical threshold, that is, provided affirmative answers to the four basic questions. These 28 papers included $24(60 \%)$ of the 40 reports published after 1990 but only $4(22 \%)$ of the 18 published before that date, thus showing a noticeable improvement over time.

On the 15 complementary questions, the mean score for the 58 papers was 47.5 points. As with the 4 basic questions, the point scoring for the 15 complementary questions improved with time: the mean was 55.1 for the 11 papers published in 1995 or later, while it was only 42.6 for the 17 published before that date.

The distribution of the 28 pieces that satisfied all four of the basic questions and thus met the minimum threshold in terms of usefulness for surveillance was: minimally useful ( $<35$ points), 16 pieces; useful (35-69 points), 8 pieces; and very useful ( $\geq 70$ points), 4 pieces.

TABLE 1. Percentage of the 58 papers reviewed that met specific methodological requirements for hypertension prevalence studies in Latin America and the Caribbean, 1962-2000

\begin{tabular}{|c|c|c|}
\hline Question & Aspect considered & Percentage \\
\hline \multicolumn{3}{|l|}{ Basic aspects } \\
\hline A & $\begin{array}{l}\text { Is the problem being studied in a general population } \\
\text { (rather than one that is captive or institutionalized)? }\end{array}$ & 75.9 \\
\hline $\mathrm{B}$ & Is the study's sampling design fully described? & 74.1 \\
\hline C & Was a probabilistic sample used? & 69.0 \\
\hline D & Are prevalences given by age groups and sex? & 67.2 \\
\hline \multicolumn{3}{|c|}{ Complementary aspects } \\
\hline 1 & $\begin{array}{l}\text { Is the problem under study described in both } \\
\text { quantitative and qualitative terms? }\end{array}$ & 63.8 \\
\hline 2 & $\begin{array}{l}\text { Were standardized techniques used to measure } \\
\text { arterial blood pressure? }\end{array}$ & 79.3 \\
\hline 3 & $\begin{array}{l}\text { Were universally accepted cut-offs used in diagnosing } \\
\text { the ailment? }\end{array}$ & 84.5 \\
\hline 4 & Did the data collectors receive training? & 58.6 \\
\hline 5 & Were certified instruments and observers used? & 46.6 \\
\hline 6 & Was there quality control of the primary data? & 41.4 \\
\hline 7 & $\begin{array}{l}\text { Were estimates calculated according to the sampling } \\
\text { design? }\end{array}$ & 25.9 \\
\hline 8 & $\begin{array}{l}\text { Were estimates made by place of residence, occupation, } \\
\text { or educational level? }\end{array}$ & 50.0 \\
\hline 9 & $\begin{array}{l}\text { Are the errors of the estimates reported according to } \\
\text { the sampling design? }\end{array}$ & 10.3 \\
\hline 10 & Are extrapolations explained or discussed? & 53.4 \\
\hline 11 & $\begin{array}{l}\text { Are any qualitative judgments made that can serve as } \\
\text { the basis for action? }\end{array}$ & 72.4 \\
\hline \multicolumn{3}{|c|}{$\begin{array}{l}\text { Hypertension-specific } \\
\text { questions }\end{array}$} \\
\hline 12 & $\begin{array}{l}\text { In addition to prevalence, was mean blood pressure } \\
\text { estimated? }\end{array}$ & 55.2 \\
\hline 13 & $\begin{array}{l}\text { Is the percentage of hypertensive individuals who know } \\
\text { of their condition indicated? }\end{array}$ & 24.1 \\
\hline 14 & $\begin{array}{l}\text { Is the percentage of hypertensive individuals under } \\
\text { treatment indicated? }\end{array}$ & 31.0 \\
\hline 15 & $\begin{array}{l}\text { Is the percentage of hypertensive individuals whose } \\
\text { disease is under control indicated? }\end{array}$ & 19.0 \\
\hline
\end{tabular}

Of these 28 studies, only 11 were published in 1995 or later.

Table 2 summarizes the results from the 11 studies published in 1995 or later that met the minimum requirements for usefulness for surveillance. While sometimes imprecise and incomplete, that information shows, as we had expected, that the problem of hypertension in LAC is common, that it seems to affect some countries more than others, and that it is more common in men than in women. Perhaps most important are the troublingly low rates of knowledge, treatment, and control among hypertensive persons, even in countries that have welldeveloped health systems.

\section{DISCUSSION}

There are at least three issues that are relevant in this discussion: 1) the limited number of papers that could be located with information on hypertension in LAC countries, 2) the methodological problems of those studies, affecting the available information and, 3) how useful the information that we found is for surveillance. There is also a fourth concern: what role does surveillance play in a strategy for hypertension prevention and control?

Without a doubt, the number of studies that we found was small, especially considering that hypertension 
TABLE 2. Results found in hypertension studies (materials published 1995-2000) in Latin America and the Caribbean classified as useful for surveillance

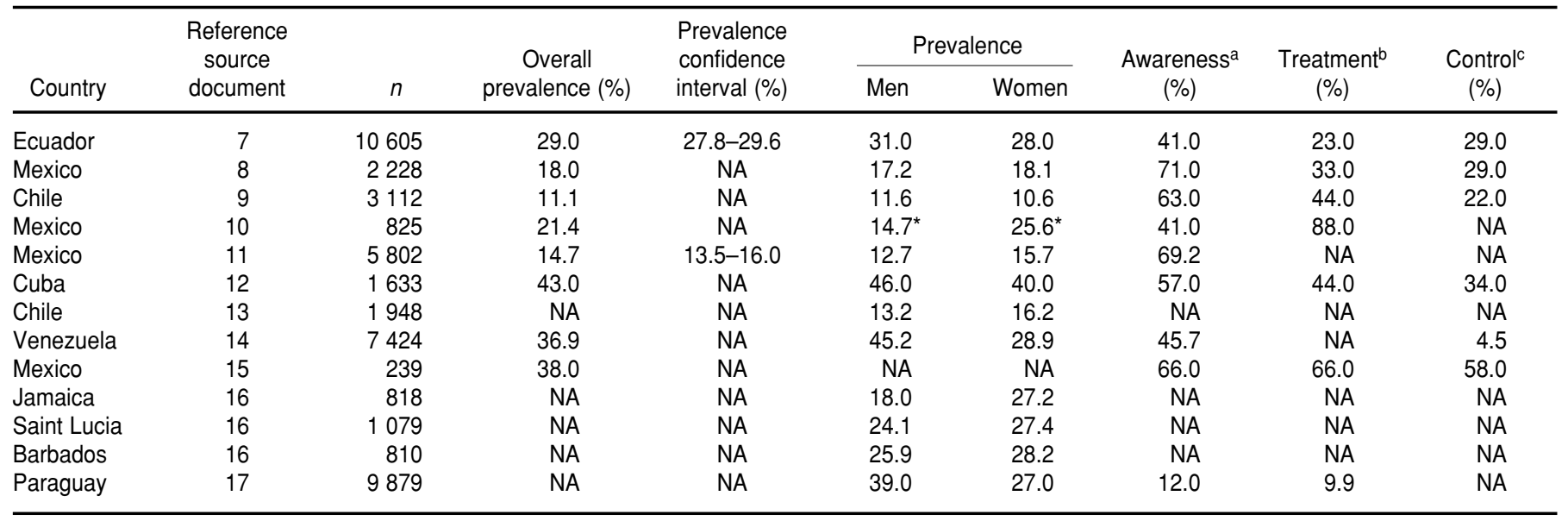

anowledge = proportion of the evaluated studies where the percentage of hypertensive individuals who were aware of their condition was indicated.

$\mathrm{b}$ Treatment = proportion of the evaluated studies where the percentage of hypertensive individuals under treatment was indicated.

${ }^{c}$ Control = proportion of evaluated studies where the percentage of hypertensive individuals whose disease was under control was indicated.

d NA = data not available (not included in the study).

is one of the principal risk factors for cardiovascular diseases, which are the leading causes of death in the majority of the LAC countries (18). It may be appealing to think that not everything that has been done in this field has been published or that it was not possible to find all of the published works, particularly when LAC has a more limited tradition of publishing articles in scientific journals. However, everything seems to indicate that what we found is an accurate reflection of the reality. We expanded our search strategy considerably and included three languages: English, Spanish, and Portuguese. We searched the most important databases and also checked such other informal sources as reports and internal publications.

However, these results are not adequate to indicate that the problem of hypertension has received little attention in LAC. In fact, we found that hypertension has been the most-studied risk factor for chronic noncommunicable diseases in LAC since 1962, or at least the one for which the most reports appear in scientific journals. In any case, the small number of published studies that met the threshold limits the usefulness that they could have for surveillance because, having been con- ducted only once, none offered the opportunity to evaluate the trend and the distribution of this problem in time and in defined population groups.

A number of the articles that we found lacked many of the needed study characteristics that we described in our earlier article on the usefulness of prevalence studies (6), especially in terms of the sampling design and the precision of the estimates. For that reason, we will only emphasize the importance of some of the aspects of measuring blood pressure and of collecting the primary data that, as we have indicated, lacked rigorous treatment in the studies that we found.

The measurement of blood pressure is a complex methodological topic (6). Blood pressure can vary from one instant to the next, changes depending upon the time of day, and is affected by environmental, physical, and psychological conditions. Another important source of variation is the person who takes the measurements, with that person's ability and level of training having a major influence. Measurement instruments are frequent sources of variation, either because of inherent problems in their design, calibration, or maintenance or because of problems in the way they are handled.
Accurate measurement is of paramount importance. For example, consistently underestimating the diastolic blood pressure by $5 \mathrm{mmHg}$ could result in almost two-thirds of hypertensive individuals being denied potentially lifesaving treatment; consistently overestimating it by $5 \mathrm{mmHg}$ could more than double the number of individuals diagnosed as hypertensive $(19,20)$. Standardized quality control and quality-assurance mechanisms for the data collection are also necessary study characteristics.

The objectives of surveillance are to monitor trends and the distribution of risk factors, examine the impact of policies and programs, and disseminate appropriate information on a timely basis (21). Given that, then the third major issue that we have raised-how useful the available information is for surveillance-is critical. In other words, if our argument that hypertension is an important public health problem is persuasive, then that leads to such questions as: What type of interventions should we recommend? What level of resources will be needed? Where and to whom should those resources be directed? How can the effectiveness of the planned actions be evaluated? In 
short, how can we guide our future actions based on the data that we have today?

Without a doubt, the available information generally does not have the ability to: 1) generate reasonably valid and reliable estimates of the prevalence of hypertension and its changes over time, 2) provide information stratified by age, gender, and socioeconomic status, 3) permit comparisons within countries and across countries over time, and ensure the quality of data collection. In addition, questions related to awareness, treatment, and control of hypertension, areas vulnerable to health actions, show very limited information to design and evaluate the public health interventions. All these attributes are essential so that given information is useful for surveillance purposes (22). No systematic effort for surveillance of hypertension in LAC is yet underway, and for this reason it is impossible to assess trends and identify population groups in which changes have occurred.

For the hypertension prevention and control programs and specifically for planning and evaluation purposes, the information about awareness, treatment and control of hypertension that we found in this study is very limited. In addition, from the point of view of the health of the entire population, measures of central tendency and dispersion provide important information. The proportion of the population exceeding any given value of a continuous variable is directly related to the mean value and the spread of the distribution in that population. For surveillance purposes, mean blood pressure is therefore as important as knowledge of the prevalence of hypertension (23). For example, a 2\% decline in the average population blood pressure will have a substantial impact in reducing both heart disease and stroke (24). All these attributes or indicators are essential so that the information given is useful for surveillance purposes (22).
Surveillance of risk factors for noncommunicable diseases (NCDs) is a relatively new component of public health practice in LAC. A number of data sets are used, each with specific strengths and limitations. Surveillance goals differ at the national, state, and local levels. The pace of demographic change and the growing societal burden of NCDs in LAC will demand attention and, one would hope, will accelerate the development of better surveillance systems.

Another factor that should be considered for surveillance systems is the current process of health care reform, of which an important aspect is the decentralization of public institutions. Local health services are being strengthened and are sometimes acquiring more resources and more decision-making authority. At the same time, the role of the central ministry of health is being redefined as that of providing leadership in its normative and regulatory functions, within a context of a separation of health care provision from health care financing.

Taking all of these factors into account, surveillance systems could provide essential information for designing, implementing, and evaluating disease prevention and control activities. This is especially true in LAC, where surveillance data are seldom available and are also frequently untimely, incomplete, and unrepresentative of populations. Further affecting the demand for surveillance data in LAC is a lack of epidemiological skills within the ministries of health.

The World Health Organization Expert Committee on High Blood Pressure Control has recommended that a major long-term goal for all countries should be to eliminate preventable cardiovascular diseases in the young and the middle-aged, and to reduce them markedly in the elderly (25). To achieve this goal, the Expert Committee suggests that control programs for high blood pressure be set up as part of a comprehensive strategy for the re- duction of total cardiovascular risk. This strategy should include the prevention of high blood pressure by measures aimed at reducing the blood pressure levels in the population as a whole, and the early identification and effective management of individuals with high blood pressure (25). Countries that accept and implement this recommendation are thus recognizing that the monitoring of risk factors, particularly hypertension, is a critical component of the strategy for health promotion and noncommunicable disease prevention.

The Pan American Health Organization (PAHO) has initiated a consultation process in order to recommend to its Member States a standard methodology for producing valid and reliable estimates of the prevalence of risk factors. This proposal offers an approach to improving surveillance by increasing the demand for high quality data, by applying the results of analysis to disease prevention and control activities, and by providing feedback to those involved in data collection. PAHO is working to create a Pan American network to monitor risk factor for NCDs, with the network providing needed quality assurance and technical support. Information from the countries that comply with the quality standards will allow comparisons between nations in the Region of the Americas.

It would be desirable for all PAHO Member States to develop systems that would provide estimates of the prevalence of hypertension and other major risk factors, as part of building a comprehensive and integrated approach to the prevention of NCDs. Since they measure changes over time, surveillance systems would eventually become an important tool in evaluating the effectiveness of prevention strategies and policies. Surveillance of NCD risk factors-particularly for hypertension-is both necessary and practical in Latin America and the Caribbean. 


\section{REFERENCES}

1. Murray CJ, Lopez AD. Alternative projections of mortality and disability by cause, 19902020: global burden of disease study. Lancet 1997:349(9064):1498-1504.

2. Stamler J, Greenland P, Neaton JD. The established major risk factors underlying epidemic coronary and cardiovascular disease. CVD Prevention 1998;1:82-97.

3. Joint National Committee on Prevention, Detection, Evaluation, and Treatment of High Blood Pressure. The sixth report of the Joint National Committee on Prevention, Detection, Evaluation, and Treatment of High Blood Pressure (JNC VI). Arch Intern Med 1997;157:2413-2446.

4. Howson CP, Reddy KS, Ryan TJ, Bale JR, eds. Control of cardiovascular diseases in developing countries. Research, development and institutional strengthening. Washington, D.C.: National Academy Press; 1998.

5. Alleyne GA, Lenfant C. The Pan American Hypertension Initiative (PAHI). WHL Newsletter 1999:68:2.

6. Silva LC, Ordúñez P, Rodríguez P, Robles S. A tool for assessing the usefulness of prevalence studies done for surveillance purposes: the example of hypertension. Rev Panam Salud Publica 2001; 10(3):152-160.

7. Cornejo C, Vinueza R, Moscoso F, Calero E, Gonzalez G, Perugachi C, et al.. Prevalence of arterial hypertension in the urban adult population of Ecuador: Quito, Guayaquil, and Cuenca - the PREHTAE Study. CVD Prevention 2000;3(1):47-58.

8. Gonzalez-Villalpando C, Stern MP, Haffner SM, Gonzalez Villapando ME, Gaskill S, Rivera Martinez D. Prevalence of hypertension in a Mexican population according to the Sixth Report of the Joint National Committee on Prevention, Detection, Evaluation and Treatment of High Blood Pressure. J Cardiovasc Risk 1999;6:177-181.
9. Vega J, Jadue L, Escobar MC, Jalil J, Espejo F, Delgado I, et al. Prevalencia de hipertensión arterial en Valparaíso. Resultados de la encuesta de base del programa CARMEN. Rev Med Chile 1999;127:729-738.

10. Yamamoto-Kimura L, Zamora-Gonzalez J, García de la Torre G, Cardoso-Saldaña G, Fajardo-Gutierrez A, Ayala-Barajas C, et al. Prevalence of high blood pressure and associated coronary risk in an adult population of Mexico City. Medical Research 1998;29(4): 341-349.

11. Guerrero-Romero JF, Rodríguez Morán M. Prevalencia de hipertensión arterial y factores asociados en la población rural marginada. Salud Publica Mex 1998;40:339-346.

12. Orduñez PO, Espinosa-Brito AD, Cooper RS, Kaufman JS, Nieto FJ. Hypertension in Cuba: evidence of narrow black-white difference. J Hum Hypertens 1998;12(2):111-116.

13. Stockins BF, Larenas GY, Charles HM, Standen DI, Spinoza OM, Illesca MP, et al. Niveles de lípidos y de presión arterial en población mapuche de la Región de la Araucanía, en Chile. Rev Med Chile 1998;126: 1291-1299.

14. Sulbaran TA, Vegas AM, Calmon GE. Aspectos epidemiológicos de la hipertensión arterial en la población adulta del Municipio de Maracaibo. Invest Clin 1997;38 Suppl 2:3-11.

15. Castro V, Gomez-Dantés H, Negrete-Sánchez J, Tapia-Conyer R. Las enfermedades crónicas en las personas de 60-69 años. Salud Publica Mex 1996;38(6):438-447.

16. Forrester T, Wilks R, Bennett F, McFarlaneAnderson N, Mcgee D, Cooper R, et al. Obesity in the Caribbean. In: Chadwick DJ Cardew GC, eds. The origins and consequences of obesity. Chichester: Wiley; 1996. pp.17-31.

17. Ramirez MO, Pino CT, Furiasse LV, Lee AJ, Fowkes FG. Paraguayan National Blood Pres- sure Study: prevalence of hypertension in the general population. J Hum Hypertens 1995; 9(11):891-897.

18. Pan American Health Organization. Health in the Americas. Volume I. Washington, D.C.: Pan American Health Organization; 1998. (PAHO Scientific Publication No. 569).

19. McAlister FA, Straus SE. Measurement of blood pressure: an evidence based review. BMJ 2001;322:908-911.

20. Campbell NR, McKay DW. Accurate blood pressure measurement: why does it matter? CMAJ 1999;161(3):277-278.

21. United States of America, Centers for Diseases Control and Prevention. CDC surveillance update. Atlanta, Georgia, United States: CDC; 1988.

22. Pan American Health Organization, Program on Non-Communicable Diseases. Networking for the surveillance of risk factors for noncommunicable diseases in Latin America and the Caribbean. Washington, D.C.: PAHO; 1999. (Publication $\mathrm{PAHO} / \mathrm{HCP} / \mathrm{HCN} / 99.05)$.

23. Bonita R, de Courten M, Dwyer T, et al. The WHO stepwise approach to surveillance (STEPS) of NCD risk factors. Geneva: World Health Organization; 2001.

24. Eastern Stroke and Heart Disease Collaborative Research Group. Blood pressure, cholesterol, and stroke in Eastern Asia. Lancet 1998; 352:1801-1807.

25. World Health Organization Expert Committee on High Blood Pressure Control. Hypertension Control. Report of a WHO Expert Committee. Geneva: WHO; 1996. (WHO Technical Report Series, No. 862).

Manuscript received 21 September 2001. Accepted for publication on 28 September 2001

RESUMEN Objetivo. Aplicar un modelo e instrumento de evaluación recién creado por los autores para evaluar con ánimo crítico la información que existe sobre la prevalencia de la hipertensión en América Latina y el Caribe y para determinar su utilidad desde el punto de vista de la vigilancia.

Cálculos de prevalencia de la hipertensión: ¿tienen utilidad para

Métodos. Se llevó a cabo una búsqueda bibliográfica de todas las publicaciones que estimaran la prevalencia de la hipertensión. Cada uno de los trabajos encontrados fue evaluado mediante el uso de un instrumento de evaluación.

Resultados. De los 58 estudios publicados entre 1966 y 2000, solamente 28 (48\%) llegaron al umbral crítico para ser considerados útiles para los fines de la vigilancia. La distribución de los 28 estudios en términos de su utilidad fue la siguiente: mínimamente útiles, 16 estudios; útiles, 8 ; y muy útiles, 4 . Se encontraron varas deficiencias metodológicas, desde técnicas de muestreo inadecuadas y tamaños muestrales inapropiados, hasta la mala calidad de los datos primarios como base para la planificación.

Discusión. Los estudios publicados sobre la prevalencia de hipertensión en América Latina y el Caribe tienen una utilidad muy limitada, en su conjunto, desde el punto de vista de la vigilancia. 